\title{
Epidural analgesia in children with cerebral palsy
}

\author{
B. Randall Brenn $M D,{ }^{*}$ \\ Robert P. Brislin DO, \\ John B. Rose MD, $†$
}

Purpose: Two modalities of epidural analgesia in children with two types of cerebral palsy (CP) were compared for differences in the incidence of common complications (inadequate analgesia, hypopnea, hypoxaemia, sedation, vomiting, pruritus, urinary retention, and seizures).

Methods: Demographic, procedural and postoperative complication data were collected on children with CP receiving epidural analgesia. Information was recorded contemporaneously with the child's care by one of the authors on 92 consecutive children with CP (age, $107 \pm 50.1$ mo; weight, $26 \pm 14.2 \mathrm{~kg}$ ) who had undergone infraumbilical orthopaedic or Nissen fundoplication procedures between December 1994 and December 1996. The first 44 patients received intermittent bolus (IB) epidural morphine and the next 48 received continuous infusion (CI) bupivacaine and fentanyl. Two forms of CP (spastic diplegia and quadriplegia) and the two modalities of analgesia were compared.

Results: Excellent analgesia was obtained in 9//92 patients. Excessive sedation occurred in six patients (6.5\%) but only in IB patients, $(P<0.02$ v $\mathrm{Cl})$. Emesis occurred in $52 \%$ of patients, and was more common in diplegic than in quadriplegic patients $(68 \%$ vs $38 \%, P<0.01$ ). Pruritus was observed in $29 \%$ of patients and was more common in diplegia than quadriplegia ( $48 \%$ vs $12.5 \%, P<0.001$ ). The incidences of hypopnea, hypoxaemia, urinary retention and seizures were not affected by the types of CP or analgesia and no difference in sedation was observed between spastic diplegic and quadriplegic patients.

Conclusions: Continuous infusion of epidural bupivacaine and fentanyl provided excellent analgesia for children with $\mathrm{CP}$ without serious complications. Intermittent bolus epidural morphine was associated with a high incidence of excessive sedation and should be avoided in this population.

Objectif : Comparer deux modes d'analgésie péridurale, chez des enfants atteints de deux types d'infirmité motrice cérébrale (IMC), selon l'incidence des complications courantes (analgésie insuffisante, hypopnée, hypoxémie, sédation, vomissements, prurit, rétention urinaire et convulsions).

Méthode : On a rassemblé les caractéristiques démographiques, opératoires et postopératoires des complications survenues pendant les interventions auprès des enfants atteints d'IMC qui ont reçu une analgésie péridurale. Ces informations ont été recueillies par l'un des auteurs au moment du traitement auprès de 92 enfants atteints d'IMC (âge : $107 \pm 50$,I mois; poids : $26 \pm 14,2 \mathrm{~kg}$ ), qui se sont successivement présentés pour subir une intervention orthopédique sous-ombilicale ou une fundoplicature de Nissen, entre décembre 1994 et décembre 1996. Les 44 premiers patients ont reçu de la morphine péridurale en bolus intermittents $(\mathrm{BI})$ et les 48 autres ont reçu une perfusion continue (PC) de bupivacaine et de fentanyl. Deux formes d'IMC (la maladie de Little et la quadriplégie) ainsi que deux modes d'analgésie ont été comparés.

Résultats : Une excellente analgésie a été obtenue chez 91 des 92 patients. Une sédation excessive a été notée chez six patients $(6,5 \%)$ mais dans le groupe $B 1$ seulement, $(P<0,02$ vs $C P)$. Chez $52 \%$ des patients, il y a eu des vomissements qui étaient plus fréquents chez les enfants diplégiques que chez les quadriplégiques $(68 \%$ vs $38 \%$, $P<0,01)$. On a observé du prurit chez $29 \%$ des enfants et surtout chez les diplégiques par rapport aux quadriplégiques ( $48 \%$ vs $12,5 \%, P<0,001$ ). Lincidence de l'hypopnée, de l'hypoxémie, de la rétention urinaire et des convulsions n'était pas influencée par le type d'IMC ou d'analgésie et aucune différence de sédation n'a été observée entre les patients diplégiques et les patients quadriplégiques.

Conclusion : La perfusion continue de bupivacaïne et de fentanyl périduraux a fourni une excellente analgésie, sans complications importantes, à des enfants atteints d'IMC. Les bolus intermittents de morphine péridurale ont été associés à une plus forte incidence de sédation excessive et on devrait éviter de les utiliser auprès de cette population.

From the Departments of Anesthesiology at the Alfred I. duPont Hospital for Children, * Wilmington, DE, and The Children's Hospital of Philadelphia, $†$ Philadelphia, PA.

Study completed at the Alfred I. duPont Hospital for Children

Address correspondence to: B. Randall Brenn MD, c/o Editorial Services, Alfred I. duPont Hospital for Children, P.O. Box 269,

Wilmington, DE 19899 USA. Phone: 302-651-5350; Fax: 302-651-5356; E-mail: brbrenn@nemours.org

Accepted for publication September 23, 1998. 


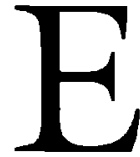

PIDURAL analgesia is used routinely to manage severe postoperative pain in healthy children. ${ }^{1-4}$ Cerebral palsy $(\mathrm{CP})$ is a disorder of movement, posture, and motor coordination caused by a central nervous system insult occurring prenatally, perinatally, or during infancy. ${ }^{5}$ Frequently, children with $\mathrm{CP}$ undergo a variety of surgical procedures including extensive orthopaedic surgery of the lower extremities and abdominal anti-reflux surgery. Although these procedures are associated with severe postoperative pain, our use of epidural analgesia in children with $\mathrm{CP}$ has been limited because of a paucity of published information on this technique in these children. The more medically compromised quadriplegic patients may be at greater risk for respiratory depression, aspiration, central nervous system depression, and seizures than diplegic patients.

Recent reviews have documented incidences of adverse events in adults ${ }^{6-8}$ and children. ${ }^{9}$ We undertook this study to compare the incidences of adverse reactions between two modalities of epidural analgesia and in two subgroups of CP.

\section{Methods and Materials}

Institutional review board approval was obtained to maintain a prospectively collected database on all children with $C P$ who received postoperative epidural analgesia. Informed consent for epidural analgesia was obtained from the legal guardians of all patients before surgery. All patients received general endotracheal anaesthesia and caudal or lumbar epidural catheters were placed after induction of general anaesthesia using standard techniques. ${ }^{10}$ The patients were not randomized in that the first 44 children received intermittent bolus (IB) preservative-free morphine and the subsequent 48 received continuous infusion (CI) of bupivacaine and $2 \mu \mathrm{g} \cdot \mathrm{ml}^{-1}$ fentanyl due to a planned change in practice. The study coincided with the development of our epidural service and initially we were only allowed to use IB on the floor until appropriate nursing acceptance of $\mathrm{CI}$ was obtained.

Patients receiving IB were given the first dose of preservative-free morphine $\left(0.04-0.05 \mathrm{mg} \cdot \mathrm{kg}^{-1}\right)$ with $0.5-1.0 \mathrm{ml} \cdot \mathrm{kg}^{-1}$ bupivacaine $0.25 \%$ intraoperatively. All but two patients received $0.04-0.05 \mathrm{mg} \cdot \mathrm{kg}^{-1}$ (one received an initial dose of $0.025 \mathrm{mg} \cdot \mathrm{kg}^{-1}$ and the other $0.085 \mathrm{mg} \cdot \mathrm{kg}^{-1}$ ). Subsequent doses of preservative-free morphine were administered every 8 to $24 \mathrm{hr}$ postoperatively for two to three days. Patients receiving CI were given $0.5-1 \mathrm{ml} \cdot \mathrm{kg}^{-1}$ bupivacaine $0.25 \%$ intraoperatively and an epidural infusion of $0.2-0.5 \mathrm{ml} \cdot \mathrm{kg}^{-1} \cdot \mathrm{hr}^{-1}$ bupivacaine $0.1 \%$ with $2 \mu \mathrm{g} \cdot \mathrm{ml}^{-1}$ fentanyl was started in the post anaesthesia care unit (PACU). Orthopaedic patients received $0.1 \mathrm{ml} \cdot \mathrm{kg}^{-1}$ diazepam $p r$ every six hours for muscle spasm in accordance with our orthopaedic department protocols. Tracheas were extubated in the operating room, and the patients were breathing spontaneously in the PACU. Following discharge from the PACU, patients were admitted to either a general medical/surgical floor or the paediatric intensive care unit (PICU) at the discretion of the attending anesthesiologist and/or surgeon.

Postoperative nursing orders consisted of hourly respiratory rate and pulse oximetry determination. Blood pressure, heart rate and sedation score (0-no sedation, 1-sleepy but easily arousable, 2 -somnolent and difficult to arouse, and 3-unable to arouse) were recorded every four hours. Urinary catheterization was performed in patients who did not void spontaneously within eight hours after surgery (in patients that did not have urinary catheters placed during surgery). Adequacy of analgesia was documented using the Children's Hospital of Eastern Ontario Pain Scale (CHEOPS ${ }^{11}$ ), and whether any rescue analgesics were required. Pain rounds were conducted twice daily. The catheters were maintained for a maximum of $72 \mathrm{hr}$ by protocol.

A three-part data sheet (demographic, procedural, and postoperative) was completed prospectively by one of the investigators on each patient. Demographic data included age, weight, gender, and type of $\mathrm{CP}$. Procedural data included surgical procedure, modality of epidural analgesia (IB or CI), the location of the epidural catheter (lumbar or caudal), and the epidural analgesics used and dose. Postoperative data included documenting the lowest respiratory rate (RR), lowest oxyhaemoglobin saturation $\left(\mathrm{sPO}_{2}\right)$, and whether or not urinary catheterization was required. All occurrences of vomiting and pruritus and the highest sedation scores were documented daily. Other complications such as seizure activity or transfer to the PICU were also recorded.

TABLE I Parameters for recording complications

\begin{tabular}{ll}
\hline Complication & Preset Criteria \\
\hline Hypopnea & $\mathrm{RR}<12 \mathrm{bpm}$ \\
Hypoxaemia & $\mathrm{sPO}_{2}<90 \%$ \\
Sedation & Sedation score 22 \\
Emesis & All instances recorded \\
Pruritus & All instances recorded \\
Urinary Retention & $\begin{array}{l}\text { Lack of spontaneous void }>8 \mathrm{hr} \text { postopera- } \\
\text { tive if the patient was not catheterized for } \\
\text { the case }\end{array}$ \\
Seizures & All instances recorded \\
\hline
\end{tabular}

$\mathrm{RR}=$ Respiratory rate

$\mathrm{sPO}_{2}=$ lowest oxyhaemoglobin saturation 
TABLE II Demographic information (values are the number and standard deviations).

\begin{tabular}{|c|c|c|c|c|c|}
\hline & All Types & Spastic Quadriplegia & Spastic Diplegia & Intermittent Bolus & Continuous Infusion \\
\hline Patients (n) & 92 & 48 & 44 & 44 & 48 \\
\hline Age (mo) & $107 \pm 50.1$ & $107 \pm 55.3$ & $105 \pm 45.3$ & $104 \pm 44.7$ & $110 \pm 55.8$ \\
\hline Weight (kg) & $26 \pm 14.2$ & $23 \pm 11.8$ & $30 \pm 15.8^{*}$ & $26 \pm 13.9$ & $26 \pm 14.7$ \\
\hline Gender $(M / F)$ & $52 / 40$ & $24 / 24$ & $28 / 16$ & $30 / 18$ & $22 / 22$ \\
\hline \multicolumn{6}{|l|}{ Procedure (n) } \\
\hline OS & 81 & 40 & 41 & 45 & 36 \\
\hline$S$ & 6 & 3 & 3 & 3 & 3 \\
\hline NF & 5 & 5 & 0 & 0 & 5 \\
\hline \multicolumn{6}{|c|}{ Epidural location ( $\mathrm{n}$ ) } \\
\hline caudal & 87 & 41 & 39 & 43 & 35 \\
\hline lumbar & 16 & 7 & 8 & 5 & 9 \\
\hline Duration (hr) & $45 \pm 11.0$ & $45 \pm 12.9$ & $45 \pm 8.5$ & $44 \pm 8.9$ & $46 \pm 12.4$ \\
\hline
\end{tabular}

$\star P$ value $<0.02$

OS = Osteotomy and soft tissuc

$S=$ Soft tissue only

$\mathrm{NF}=$ Nissen fundoplication

TABLE III Incidences of complications by cerebral palsy type and modality of analgesia (values are number of patients; percentages are shown in parentheses).

\begin{tabular}{llllll}
\hline & All Patients & Spastic Quadriplegia & Spastic Diplegia & Continuous Infusion & Intermittent Bolus \\
\hline $\begin{array}{l}\text { Patients } \\
\begin{array}{l}\text { Hypopnea } \\
(\mathrm{RR}<12)\end{array}\end{array}$ & $92(100)$ & $48(52)$ & $44(48)$ & $44(48)$ & $48(52)$ \\
$\begin{array}{l}\text { Hypoxaemia } \\
(\text { sPO } 2<90)\end{array}$ & $6(6.5)$ & $4(8.3)$ & $2(4.3)$ & $3(6.8)$ & $3(6.3)$ \\
$\begin{array}{l}\text { Sedation } \\
(\text { Score 2 2) }\end{array}$ & $7(7.6)$ & $4(4.2)$ & $5(11.4)$ & $4(9)$ & $3(6.3)$ \\
$\begin{array}{l}\text { Emesis } \\
\text { Pruritus }\end{array}$ & $6(6.5)$ & $4(8.3)$ & $2(4.3)$ & $0(0)$ & $6(12.5)^{\star}$ \\
$\begin{array}{l}\text { Urinary Retention } \\
(\mathrm{n}=57)\end{array}$ & $48(52)$ & $18(38)$ & $30(68) \dagger$ & $24(55)$ & $24(50)$ \\
Seizures & $27(29)$ & $6(12.5)$ & $21(48) \ddagger$ & $10(23)$ & $17(35)$ \\
\hline
\end{tabular}

$* P<0.01$

$\dagger P<0.01$

$\ddagger P<0.001$

The modalities of epidural analgesia (IB and CI) and the $\mathrm{CP}$ types (diplegia and quadriplegia) were compared for differences in the incidence of complications. Criteria for each complication are given in Table I. The statistical analysis was performed using SPSS for Windows (Statistical Product \& Service Solutions, Chicago, IL). Ordinal data were analyzed using chi square analysis. Nominal data were analyzed with student's $t$ test for independent samples. In all cases, a $95 \%$ confidence interval was sought to determine statistical significance.

\section{Results}

Data were collected on 92 consecutive patients between December 1994 and December 1996. Ninety-one of the 92 patients were judged to have good pain control. One diplegic patient who had a bilateral procedure experienced a unilateral block that could not be improved. All patients were discharged from the PACU, breathing room air, to an inpatient unit or initially to the PICU, as was the protocol for Nissen fundoplication (NF) patients, and then to the floor.

Demographic and procedural data are summarized in Table II. The types of surgery were distributed into three general categories: lower extremity osteotomy with or without soft tissue releases (OS), lower extremity soft tissue releases only (S), and NF with or without soft tissue releases. No differences were found between IB and CI patients with respect to gender, 
age, and weight. There were no differences in gender or age between the diplegic and quadriplegic patients. However, the diplegic patients weighed more than the quadriplegics $(P<0.02)$. Seventy-eight $(85 \%)$ patients had catheter placement by the caudal route, whereas 14 (15\%) had lumbar catheters placed. The epidural catheters were maintained for an average of $45 \mathrm{hr}$ (range, 24-68 hr). There was no difference in the duration of epidural catheterization between the diplegic and quadriplegic patients or between the IB and CI groups.

Complication incidences are shown in Table III. Hypopnea occurred in $6.5 \%$ of patients. There was no difference between the lowest RR for modality of analgesia or type of CP. Seven patients $(7.6 \%)$ had lowest recorded $\mathrm{sPO}_{2}<90 \%$. Only one patient had concomitant hypopnea. No difference in lowest $\mathrm{sPO}_{2}$ was seen between the modalities of analgesia, or between patients with diplegia or quadriplegia.

Six patients $(6.5 \%$ overall) had moderate to severe sedation, and all occurred in the IB group, $(P<0.01)$. Two patients were transferred to the PICU for further observation of sedation status. There was no difference in sedation between the types of CP. The overall incidence of emesis was $52 \%$. The incidence of vomiting in diplegics was greater than in the quadriplegic patients $(68 \%$ vs $38 \%, P<0.01)$. The incidence of vomiting between IB and CI was comparable (50\% and $\mathbf{5 5 \%}$, respectively). The incidence of pruritus was $29 \%$ and was greater in the diplegic than in the quadriplegic patients $(48 \%$ vs $12.5 \%, P<0.0002)$. Pruritus appeared to be more frequent in the IB group than the CI group ( $35 \%$ ps $23 \%$ ), but the difference was not statistically significant $(P<0.18)$.

Thirty-five patients were excluded from analysis of urinary retention because they had catheters placed intraoperatively that were continued into the postoperative period. Of the remaining 57 uncatheterized patients, $40(70 \%)$ required catheterization postoperatively because of inability to void within eight hours postoperatively. There was no difference in the rate of catheterization between the types of patients and modality of epidural analgesia.

Two patients from the CI group, one diplegic and the other quadriplegic, had seizures during the postoperative period, but there was no difference in the seizure incidence between types of CP and modality of epidural analgesia.

\section{Discussion}

Children with $\mathrm{CP}$ often have pre-existing medical problems that can complicate the management of conventional intravenous or epidural analgesia during the postoperative period. We employed a retrospective review of a prospectively collected database to compare the incidence of complications associated with epidural analgesia in 92 patients with spastic diplegia or quadriplegia who received either IB narcotic or CI bupivacaine and opioid. We were not blinded to the modalities employed or to the type of CP. This could have contributed to bias in our analysis. Our population size also limits the strength of our conclusions. The goal was to document complications according to preset criteria in this difficult population.

The incidence and severity of vomiting and pruritus were higher in the diplegic patients than in the quadriplegic patients and were not related to the modality of analgesia. The incidence of sedation was higher in the IB than in the CI patients, but was independent of the type of CP. There was no difference in the incidence of hypopnea, oxygen desaturation, urinary retention, or seizures between the two types of CP or modalities of epidural analgesia at the doses studied.

Studies of the complications of epidural analgesia in children with CP are limited. Single shot epidural morphine $\left(40 \mu \mathrm{g} \cdot \mathrm{kg}^{-1}\right)$ was compared with epidural buprenorphine $\left(3 \mu \mathrm{g} \cdot \mathrm{kg}^{-1}\right)$, butorphanol $\left(30 \mu \mathrm{g} \cdot \mathrm{kg}^{-1}\right)$, and control patients in 85 children with CP. ${ }^{12}$ Each of the experimental groups had superior analgesia with no increase in sedation, nausea and vomiting, and pruritus. Intermittent bolus epidural morphine has also been studied in CP children undergoing dorsal rhizotomy for spasticity. Sparkes et al. ${ }^{13}$ showed the efficacy of IB morphine in 28 children following selective dorsal root rhizotomy. This group recorded incidences of emesis and pruritus of $38 \%$, but they reported no sedation or respiratory depression, and all patients received urinary catheters. Lawhorn et al. ${ }^{14}$ compared $80 \mu \mathrm{g} \cdot \mathrm{kg}^{-1}$ of morphine with $80 \mu \mathrm{g} \cdot \mathrm{kg}^{-1}$ morphine and $40 \mu \mathrm{g} \cdot \mathrm{kg}^{-1}$ butorphanol in 14 post-rhizotomy patients. They documented reductions in the incidences of nausea and vomiting ( $85 \%$ to $14 \%$ ), pruritus ( $57 \%$ to $0 \%$ ), and oxygen desaturation ( $57 \%$ to $0 \%$ ), when butorphanol was added. To our knowledge, there are no reports of the use of $\mathrm{CI}$ in patients with $\mathrm{CP}$ and no comparisons of IB with $\mathrm{CI}$ in this population.

Respiratory depression from neuraxial opioids can have an early onset from systemic absorption of drug, or delayed onset from cephalad spread of the hydrophilic morphine to the ventral medulla. Review articles of adults have placed the incidence of respiratory depression requiring intervention at $1 \%$ for epidural opioids ${ }^{6,7}$ and $1.2 \%^{8}$ for fentanyl/bupivacaine infusions, and $0.5 \%$ in children. ${ }^{9}$ We documented higher incidences of hypopnea and desaturation, possibly because of preexisting pulmonary disease in our 
population or because we set out specifically to document our complications with preset criteria.

Sedation with neuraxial opioids is commonly associated with sufentanil administration, ${ }^{7}$ and may herald the onset of respiratory depression presumably from the effects of the opioid on higher centres or by increasing hypercarbia. Scott $e t a l .{ }^{8}$ and Wood $e t a l .^{9}$ reported incidences of sedation of $7.4 \%$ and $6.3 \%$ in adults and children, respectively, who received $\mathrm{CI}$. We were concerned that children with $C P$, especially those with more severe mental retardation, would be at particular risk of sedation. This, combined with the use of diazepam for postoperative spasm, heightened our awareness of this problem. However, we found no differences in sedation scores between the types of $\mathrm{CP}$, but patients who received IB morphine had a greater incidence of sedation than those who received CI. Thus, we recommend the use of $\mathrm{CI}$, which may preserve mental capabilities because of the lack of cephalad spread of neuraxial opioid.

Published reports give incidences of nausea and vomiting of $30 \%$ to $100 \%$ in adults, ${ }^{6,7}$ and of $23 \%$ in children..$^{9}$ It is believed that it is due to the cephalad migration of the agents and their effects on the area postrema opioid receptors. The incidence of emesis may be decreased when agonist-antagonist medications are used. ${ }^{14}$ Our overall incidence of $52 \%$ is similar to previous reports. We did not detect any differences between the two major modalities, but quadriplegic patients had fewer episodes of emesis. Quadriplegic patients have a higher incidence of gastroesophageal reflux and Nissen fundoplications and may not be able to vomit after the anti-reflux measures are instituted. In our population, however, only five of the quadriplegic patients and one of the diplegic patients had had pre-existing fundoplication.

The incidence of pruritus varies widely from $0 \%$ to $100 \%$ in adult patients ${ }^{6-8}$ and occurs in about $5 \%$ of children. ${ }^{9}$ Cephalad spread to the trigeminal nucleus is the suggested mechanism of opioid related pruritus. Stimulation at this level causes the characteristic itching of the face and upper chest. There has been a suggestion that the use of epidural local anaesthetics may reduce the incidence of pruritus. We documented an overall incidence of $29 \%$ with no differences between the modality of epidural analgesia used. However, the greater incidence of pruritus observed in the diplegic patients may be due to their ability to manifest itching by scratching or verbalization.

Although there was no difference between the groups, our overall incidence of urinary retention $(70 \%)$ seems very high when compared with that of normal children $\left(6.3 \%^{9}\right)$ and adults $\left(0 \%\right.$ to $\left.80 \%^{7}\right)$. Opioid and local anaesthetic inhibition of sacral parasympathetic outflow causes detrusor relaxation and enlarged bladder capacity. Children with $\mathrm{CP}$ are predisposed to urinary problems of incontinence, frequency, and urgency. ${ }^{15,16}$ Urodynamic findings have shown small, hyper-reflexic bladders, difficulty with relaxation of the pelvic floor, and to a lesser extent detrusor sphincter dysyinergia. ${ }^{15,16}$ Impairment of sensation and bladder relaxation may contribute to these patients' inability to void after epidural analgesia. This high rate of postoperative urinary catheterization has caused some of our surgeons to always use indwelling catheters until the epidural catheters are removed.

Seizures with $\mathrm{CI}$ in infants and children ${ }^{17,18}$ have been associated with bupivacaine infusion usually in excess of $0.5 \mathrm{mg} \cdot \mathrm{kg}^{-1} \cdot \mathrm{hr}^{-1} \cdot{ }^{19}$ We were encouraged that we did not have greater problems with seizures, given that $50 \%$ of our population had a seizure history. This may be because our infusion rates $\left(0.2-0.5 \mathrm{mg} \cdot \mathrm{kg}^{-1} \cdot \mathrm{hr}^{-1}\right)$ were below those that have been associated with seizures, or the use of the anticonvulsant diazepam for spasm.

\section{Conclusions}

Children with $\mathrm{CP}$ have considerable pain and spasm after orthopaedic and general surgical operations, and may have other medical problems that put them at risk when they receive parenteral pain medication. In our experience, the continuous epidural infusion of bupivacaine $0.1 \%$ with $2 \mu \mathrm{g} \cdot \mathrm{kg}^{-1}$ fentanyl provides good analgesia with few side effects. Our routine monitoring detected problems early, allowing for timely intervention of adverse events. Compared with continuous infusions of local anaesthetic and opioid, IB morphine was associated with more sedation, and we do not recommend its use in children with $\mathrm{CP}$.

\section{Acknowledgments}

We wish to thank Mr. Bruce M. Brenn for his translation of selected scientific articles from the original Japanese.

\section{References}

1 Ecoffey $C$, Dubousset $A-M$, Samii $K$. Lumbar and thoracic epidural anesthesia for urologic and upper abdominal surgery for infants and children. Anesthesiology 1986; 65: 87-90.

2 Desparmet J, Meistleman C, Barre J, Saint-Maurice C. Continuous epidural infusion of bupivacaine for postoperative pain relief in children. Anesthesiology 1987; 67: $108-10$

3 Dalens $B$, Tanguy $A$, Haberer J-P. Lumbar epidural anesthesia for operative and postoperative pain relief in infants and young children. Anesth Analg 1986; 65: 1069-73. 
4 Murat I, Delleur MM, Esteve C, Egu JF, Raynaud $P$, Saint-Maurice $C$. Continuous extradural anaesthesia in children. Br J Anaesth 1987; 69: 1441-50.

5 Eicher PS, Batshaw ML. Cerebral palsy. Paediatr Clin North Am 1993; 40: 537-51.

6 Liu S, Carpenter RL, Neal JM. Epidural anesthesia and analgesia. Their role in postoperative outcome. Anesthesiology 1995; 82: 1474-506.

7 Chaney MA. Side effects of intrathecal and epidural opioids. Can J Anaesth 1995; 42: 891-903.

8 Scott DA, Beilby DSN, McClymont C. Postoperative analgesia using epidural infusions of fentanyl with bupivacaine. A prospective analysis of 1,014 patients. Anesthesiology 1995; 83: 727-37.

9 Wood CE, Goresky GV, Klassen KA, Kuwahara B, Neil $S G$. Complications of continuous epidural infusions for postoperative analgesia in children. Can J Anaesth 1994; 41: 613-20.

10 Dalens $B$. Caudal anesthesia and lumbar epidural anesthesia. In: Dalens B (Ed.). Regional Anesthesia in Infants, Children, and Adolescents. Baltimore: Williams \& Wilkins, 1995: 171-248.

11 McGrath PJ, Jobnson G, Goodman J, et al. The Children's Hospital of Eastern Ontario Pain Scale (CHEOPS): a behavioral scale for rating pain in children. In: Fields H, Dubner R, Cervero F (Eds.). Advances in Pain Research and Therapy, Vol. 9. New York: Raven Press, 1985: 395-402.

12 Obta K, Katsuno M, Kawana S, Namiki A. Epidural opioids for postoperative pain control in pediatric patients with cerebral palsy. Masui 1993; 42: 664-8.

13 Sparkes $M L$, Klein AS, Dubaime A-C, Mickle JP. Use of epidural morphine for control of postoperative pain in selective dorsal rhizotomy for spasticity. Pediatric Neuroscience 1989; 15: 229-32.

14 Lawhorn $C D$, Boop $F$, Brown $R$, Andelman P. Epidural pain management in the postrhizotomy patient. Pediatr Neurosurg 1994; 20: 198-202.

15 Reid $C J D$, Borzyskowski $M$. Lower urinary tract dysfunc tion in cerebral palsy. Arch Dis Child 1993; 68: 739-42.

16 Mayo ME. Lower urinary tract dysfunction in cerebral palsy. J Urol 1992; 147: 419-20.

17 McCloskey JJ, Haun SE, Deshpande JK. Bupivacaine toxicity secondary to continuous caudal epidural infusion in children. Anesth Analg 1992; 75: 287-90.

18 Agarwal R, Gutlove DP, Lockbart CH. Seizures occurring in pediatric patients receiving continuous infusion of bupivacaine. Anesth Analg 1992; 75: 284-6.

19 Berde CB. Convulsions associated with pediatric regional anesthesia. Anesth Analg 1992; 75: 164-6. 